\title{
ỨNG DỤNG MÔ HÌNH DIỄN TOÁN SWAT/NAM/MIKE XÂY DỬNG BỘ THÔNG SỐ THỦY VĂN VÀ THỦY LỰC PHỤC VỤ CHO TÍNH TOÁN DÒNG CHẢY - TRƯỜNG HợP SÔNG VỆ, QUẢNG NGÃI
}

\author{
Lê Thị Mỹ Diệp ${ }^{1}$, Bùi Huỳnh Anh², Bùi Tá Long²*
}

Tóm tắt: Khu vục duyên hải tỉnh Quảng Ngãi đang có tốc độ tăng trương kinh tế khá nhanh. Trước ảnh hương của biến đổi khi hậu (BĐKH), tình trạng ngập lụt và xâm nhập mặn đang diê̂n biến phức tạp. Cả hai loại hình này đều yêu cầu phải tính toán và dụ báo diê̂n biến dòng chảy, do vậy là đối tượng nghiên cưu của nhiều tác giả. Trong nghiên cứu này đề xuất một qui trình các buớc tính ưng dụng hệ các mô hình diễn toán SWAT, NAM và MIKE, kết hợp với các dũ liệu đo đạc thực tế, cùng các bước hiệu chỉnh và kiểm định xây dụng bộ hẹ số thủy văn và thủy lực phục vụ cho tính toán dòng chảy sông Vệ, Quảng Ngãi. Kết quả hiệu chỉnh và kiểm định được thực hiện dụ trên các chỉ số thống kê được sủ dụng rộng rãi trong thủy văn cho phép khẳng định khả năng áp dụng thực tế là chấp nhận được. Điểm mới của nghiên cưu này so với các nghiên cứu truớc được thể hiện trên so' đồ tích hợp, trong đó thể hiện rõ sự kết hợp giữa số liệu, mô hình và buớc hiệu chỉnh bộ thông số thủy văn và thủy lực.

Từ khóa: Mô hìn mura - dòng chảy, SWAT, NAM, MIKE, sông Vệ.

Ban Biên tập nhận bài: 09/04/2019 Ngày phản biện xong: 20/6/2019 Ngày đăng bài: 25/06/2019

\section{1. Đặt vấn đề}

Vùng duyên hải tỉnh Quảng Ngãi bao gồm các huyện Bình Sơn, Sơn Tịnh, Tư Nghĩa, Mộ Đức, Đức Phổ và Tp.Quảng Ngãi. Nhờ thiên nhiên ưu đãi cùng với vị trí địa lý thuận lợi mà các huyện trên có tốc độ tăng trưởng kinh tế khá nhanh. Tuy nhiên, trong những năm qua trước ảnh hưởng của $\mathrm{BĐKH}$, tình trạng ngập lụt và xâm nhập mặn tại khu vực này diễn biến phức tạp, do vậy đây là đối tượng nghiên cứu của nhiều đề tài, dự án các cấp. Trong xây dựng công nghệ dự báo lũ lớn và cảnh báo ngập lụt hệ thống sông Vệ - Trà Khúc trong khuôn khổ đề tài cấp nhà nước [1]. Quá trình động lực và diễn biến hình thái tại cửa Lở được thực hiện trong [3-4]. Nghiên cứu về dòng chảy và ảnh hưởng tiêu thoát lũ tỉnh Quảng Ngãi khi xây dựng tuyến đường cao tốc Đà Nẵng - Quảng Ngãi được thực

${ }^{1}$ Viện Khoa học và Thủy lợi Miền Nam

${ }^{2}$ Trưòng Đại hoc Bách Khoa Tp. HCM

Email:longbt62@hcmut.edu.vn hiện trong [5]. Nghiên cứu mô hình dự báo thủy văn sông Trà Khúc được thực hiện trong [6]. Đặc biệt, trong nghiên cứu [2] nhóm tác giả đã thực hiện xác định bộ thông số thủy văn và thủy lực cho lưu vực sông Trà Khúc và sông Vệ. Một điểm chung của các nghiên cứu trên là ứng dụng nhiều mô hình thủy văn khác nhau như NAM, MARINE, SWAT,... Trong tính toán thủy văn, các mô hình "mưa rào - dòng chảy" thường được sử dụng rộng rãi dù rằng, mô hình hóa nó luôn là nhiệm vụ phức tạp bởi các quá trình đang diễn ra trong một hệ thống thủy văn rất phức tạp, chưa được biết đầy đủ [7]. Một số mô hình dòng chảy "mưa rào - dòng chảy" được nghiên cứu trong các nghiên cứu của tác giả ngoài nước [8-14]. Tại Việt Nam, có nhiều nghiên cứu áp dụng NAM dự báo dòng chảy từ mưa cho các lưu vực sông khác nhau. Nghiên cứu [15] ứng dụng NAM dự báo dòng chảy cho sông Ba, Phú Yên phục vụ đánh giá tài nguyên nước cho lưu vực. Nghiên cứu của nhóm tác giả [16-17] ứng dụng 
NAM dự báo dòng chảy lưu vực sông Cả, Bình Định và khu vực hạ lưu sông Sài Gòn. Theo nghiên cứu [18], trong những thập kỷ qua, hàng trăm mô hình "mưa rào - dòng chảy" được đề xuất với mục đích ứng dụng thời gian thực. Các mô hình này được phân loại theo quy mô thời gian - không gian, theo phương pháp giải phương trình được sử dụng. Các tính năng chính để phân biệt cách tiếp cận là: các thuật toán cơ bản (dựa trên kinh nghiệm, khái niệm hoặc dựa trên quá trình); cách tiếp cận: ngẫu nhiên hoặc tiền định [7]. Trong nghiên cứu này, ứng dụng hệ thống các mô hình diễn toán SWAT/NAM/MIKE21 HD nhằm xác định bộ thông số thủy văn và thủy lực đạt yêu cầu tại khu vực cửa sông Vệ - bước đi đầu tiên cho nghiên cứu mô phỏng xâm nhập mặn tại khu vực cửa sông Vệ, trong khuôn khổ đề tài nghiên cứu sinh. liệu

\section{Phương pháp nghiên cứu và thu thập tài}

\subsection{Giới thiệu về khu vục nghiên cưu}

\section{BẢN ĐÒ NHÁNH CHINH VÀ CÁC NHÁNH PHỤ HợP LƯU}

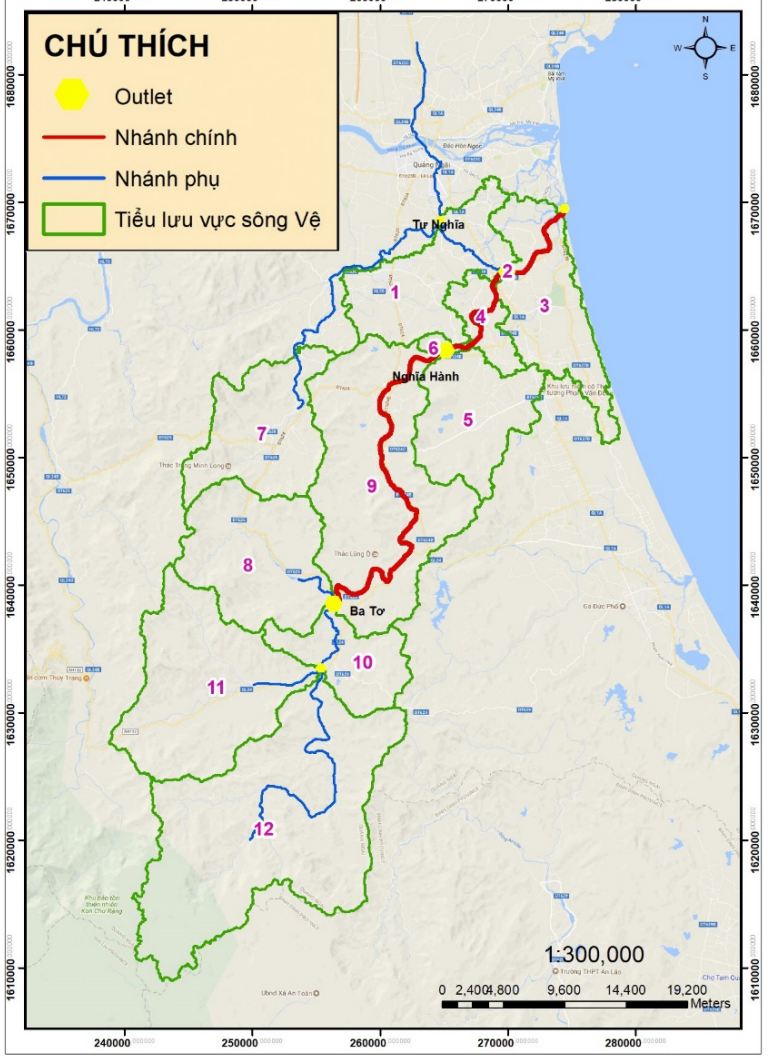

Hình 1. Vị trí, giới hạn khu vục nghiên cứu với 12 tiểu lư vục [19]
Sông Vệ bắt nguồn từ rừng núi phía Tây, chảy theo hướng Tây Nam - Đông Bắc, giữa các huyện Tư Nghĩa, đổ ra biển Đông tại cửa Cổ Lũy và cửa Đức Lợi. Phía Bắc và phía Tây giáp sông Trà Khúc, phía Nam giáp tỉnh Bình Định và phía Đông giáp biển. Lưu vực sông Vệ có diện tích khoảng $1260 \mathrm{~km}^{2}$, sông chính có chiều dài khoảng $90 \mathrm{~km}$ trong đó có $2 / 3$ chiều dài chảy trong vùng núi có độ cao 100 - 1000m, mật độ sông suối trong lưu vực đạt $0,79 \mathrm{~km} / \mathrm{km}^{2}$, độ dốc bình quân lưu vực khoảng 19,9\% [19]. Thực vật che phủ bề mặt lưu vực vùng thượng lưu phần lớn là rừng già, bụi rậm, vùng hạ lưu chủ yếu là vùng đất canh tác nông nghiệp. Hình 1 thể hiện vị trí và phạm vi của nghiên cứu.

\subsection{Mô hình SWAT, MIKE NAM, MIKE 21} HD

\subsubsection{Mô hình SWAT}

SWAT (Soil and Water Assessment Tool) là công cụ đánh giá nước và đất, được xây dựng bởi Trung tâm phục vụ nghiên cứu nông nghiệp (ARS - Agricultural Research Service). Mô hình giúp đánh giá và dự đoán các tác động sư dụng đất đai tác động đến nguồn nước, phù sa, và lượng hóa chất trong nông nghiệp sinh ra trên một lưu vực rộng lớn và phức tạp. Mô hình mô phỏng nhiều quá trình vật lý trong cùng một lúc trên lưu vực và cho phép mô phỏng với mức độ chi tiết hóa cao bằng cách chia lưu vực thành các tiểu lưu vực theo địa hình và mặng lưới thủy văn, sau đó mỗi tiểu lưu vực được phân chia thành các đơn vị thủy văn (Hydrological response units - HRUs) có những đặc trưng riêng duy nhất về đất và sử dụng đất dựa vào loại đất và lớp phủ thực vật bên trong tiểu lưu vực.. Sự phân chia này giúp người sử dụng có thể áp dụng kết quả nghiên cứu của một vùng này vào một vùng khác khi chúng có sự tương đồng nhất định. Trong nghiên cứu này, SWAT kết hợp với ArcGIS được sử dụng để phân lưu vực, phân tích đơn vị thủy văn, biên tập dữ liệu khí tượng (vận tốc gió, lượng mưa, nhiệt độ max/min, độ ẩm, cường độ bức xạ). Kết quả chạy SWAT trong nghiên cứu này được thể hiện trong [19]. Một số kết quả tương tự ứng dụng SWAT của nhóm tác giả thể 
hiện trong công bố khoa học [20].

\subsubsection{Mô hình thủy văn NAM}

Trong nghiên cứu này sử dụng hệ thống mô hình thủy lực và thủy văn nên trước tiên sẽ tổng quan về các công cụ được sử dụng. Hệ thống dự báo thủy văn - thủy lực trong Mike11 gồm các modules: (1) Mưa rào - dòng chảy (Rain - Runnoff hay còn ký hiệu là RR), (2) Thủy lực (Hydrodynamic - HD), (3) Quy trình Flood Forecasting (FF). Mô hình NAM (viết tắt của cum tù Nedbør-Afstrømnings-Model) là một phần trong hệ thống mô hình mô phỏng kênh sông Mike11. Mô hình có tên gọi "mưa rào dòng chảy" là một mô hình tập trung gồm nhiều module con, đã được đóng gói, mô phỏng dòng chảy trên mặt đất, các dòng kết nối với nhau, và với dòng chảy chính. Module RR có thể được áp dụng độc lập hoặc được sử dụng để thể hiện một hoặc nhiều lưu vực gia nhập vào mạng lưới sông. Module FF được thiết kế để dự báo sự thay đổi mực nước và lưu lượng trong hệ thống kênh sông do quá trình "mưa rào - dòng chảy".

Mô hình NAM là mô hình cải tiến từ mô hình Nielsen-Hansen, được công bố trong tạp chí "Nordic Hydrology" năm 1973, sau này được Viện Thủy lực Đan Mạch phát triển và đổi thành NAM (tù 3 tù̀ viết tắt tiếng Đan Mach: NedbørAfstrømnings-Model). Mô hình gồm 4 bể chứa, nguyên lý tính toán trong mỗi bể chứa là giải phương trình cân bằng theo quy luật phi tuyến (dạng đường cong nước rút). Mô hình NAM mô phỏng quá trình mưa - dòng chảy một cách liên tục thông qua việc tính toán cân bằng nước ở bốn bể chứa thẳng đứng, có tác dụng qua lại lẫn nhau để diễn tả các tính chất vật lý của lưu vực. Các bể chứa đó gồm: Bể tuyết (chỉ áp dụng cho vùng có tuyết); Bể mặt; Bể sát mặt hay bể tầng rễ cây; Bể ngầm Dữ liệu đầu vào của mô hình là mưa, bốc hơi tiềm năng, và nhiệt độ. Kết quả đầu ra của mô hình là dòng chảy trên lưu vực, mực nước ngầm, và các thông tin khác trong chu trình thuỷ văn, như sự thay đổi tạm thời độ ẩm của đất và khả năng bổ xung nước ngầm. Dòng chảy lưu vực được phân một cách gần đúng thành dòng chảy mặt, dòng chảy sát mặt, dòng chảy ngầm. Mô hình NAM thuộc loại mô hình tất định, thông số tập trung, và là mô hình mô phỏng liên tục. Trong nghiên cứu này, NAM được sử dụng để tạo ra biên thủy lực cho mô hình thủy lực MIKE21 HD. Một số kết quả thuộc mực này được thể hiện trong [19].

\subsubsection{Mô hìn thủy lực Mike 21 HD}

MIKE 21 HD do DHI [27] thực hiện là phần mềm kỹ thuật để tính toán dòng chảy, trong sông, hồ, cửa sông, vịnh, các vùng biển ven bờ và ngoài khơi. Phương trình toán trong MIKE21 HD được viết cho dòng hai chiều không đồng nhất trong một lớp chất lỏng đồng nhất theo phương thẳng đứng dựa trên phương trình Navier-Stokes, Reynolds không nén 3 chiều với các giả định Boussinesq và áp suất thủy tĩnh.

Phương trình liên tục:

$$
\frac{\partial \mathrm{h}}{\partial \mathrm{t}}+\frac{\partial \mathrm{hU}}{\partial \mathrm{x}}+\frac{\partial \mathrm{hV}}{\partial \mathrm{y}}=\mathrm{hS}
$$

Các phương trình động lượng theo phương ngang gồm

$$
\begin{gathered}
\frac{\partial \mathrm{h}}{\partial \mathrm{t}}+\frac{\partial \mathrm{hU^{2 }}}{\partial \mathrm{x}}+\frac{\partial \mathrm{hUV}}{\partial \mathrm{y}}=\mathrm{fVh} \\
-\mathrm{gh} \frac{\partial \eta}{\partial \mathrm{x}}-\frac{\mathrm{h}}{\rho_{0}} \frac{\partial \mathrm{p}_{\mathrm{a}}}{\partial \mathrm{x}}-\frac{\mathrm{gh}^{2}}{2 \rho_{0}} \frac{\partial \rho}{\partial \mathrm{x}}+\frac{\tau_{\mathrm{xx}}}{\rho_{0}}-\frac{\tau_{\mathrm{bx}}}{\rho_{0}}-\frac{1}{\rho_{0}}\left(\frac{\partial \mathrm{S}_{\mathrm{xx}}}{\partial \mathrm{x}}+\frac{\partial \mathrm{S}_{\mathrm{xy}}}{\partial \mathrm{x}}\right) \\
+\frac{\partial}{\partial \mathrm{x}}\left(\mathrm{hT}_{\mathrm{xx}}\right)+\frac{\partial}{\partial \mathrm{y}}\left(\mathrm{hT}_{\mathrm{xy}}\right)+\mathrm{hU}_{\mathrm{s}} \mathrm{S} \\
\frac{\partial \mathrm{hV}}{\partial \mathrm{t}}+\frac{\partial \mathrm{hV}}{\partial \mathrm{x}}+\frac{\partial \mathrm{hUV}}{\partial \mathrm{y}}=-\mathrm{fUh}-\mathrm{gh} \frac{\partial \eta}{\partial \mathrm{y}}-\frac{\mathrm{h}}{\rho_{0}} \frac{\partial \mathrm{p}_{\mathrm{a}}}{\partial \mathrm{y}}-\frac{\mathrm{gh}^{2}}{2 \rho_{0}} \frac{\partial \rho}{\partial \mathrm{y}}+\frac{\tau_{\mathrm{xx}}}{\rho_{0}}-\frac{\tau_{\mathrm{bx}}}{\rho_{0}}-\frac{1}{\rho_{0}}\left(\frac{\partial \mathrm{S}_{\mathrm{xx}}}{\partial \mathrm{x}}+\frac{\partial \mathrm{S}_{\mathrm{xy}}}{\partial \mathrm{x}}\right) \\
+\frac{\partial}{\partial \mathrm{x}}\left(\mathrm{hT}_{\mathrm{xy}}\right)+\frac{\partial}{\partial \mathrm{y}}\left(\mathrm{hT}_{\mathrm{yy}}\right)+\mathrm{hV}_{\mathrm{s}} \mathrm{S}
\end{gathered}
$$


Trong đó $\mathrm{U}, \mathrm{V}$ là các thành phần vận tốc trung bình theo độ sâu của các thành phần vận tốc $\mathrm{u}, \mathrm{v}$ theo các phương tọa độ $\mathrm{x}, \mathrm{y}$; $\mathrm{t}$ là thời gian; $\mathrm{h}=\eta+\mathrm{d}$ : với là mực nước, $\mathrm{d}$ độ sâu. Với $\mathrm{T}_{\mathrm{xx}}, \mathrm{T}_{\mathrm{xy}}, \mathrm{T}_{\mathrm{yy}}$ là các thành phần ứng suất nhớt tổng cộng của nhớt thuần túy, nhớt rối và khuếch tán. $\mathrm{S}$ là thành phần lưu lượng từ nguồn thải điểm; $\mathrm{U}_{\mathrm{s}}$, $\mathrm{V}_{\mathrm{s}}$ là các thành phần tốc độ nguồn thải do nguồn điểm; g là gia tốc trọng trường; $f=2 \Omega \sin \phi$ là tham số Coriolis; $\rho$ là mật độ nước, $\rho_{0}$ là mật độ tiêu chuẩn; $\mathrm{p}_{\mathrm{a}}$ là áp suất khí quyển. Hệ thống các phương trình trên được giải theo thuật toán thể tích hữu hạn với lưới mềm dẻo.

\subsection{Thu thập tài liệu và thiết lập mô hình}

\subsubsection{Dũ liệu lư vục}

Dữ liệu DEM được lấy từ trang web http://gdex.cr.usgs.gov/gdex/ và sử dụng phần mềm SWAT phân chia khu vực nghiên cứu thành các lưu vực, sử dụng ArcGIS số hóa đoạn sông. Sau khi phân chia lưu vực nhận được số liệu dưới dạng shapefile tiểu lưu vực. Các kết quả này được trình bày trong [19].

\subsubsection{Dũ liệu địa hình chạy MIKE}

Dữ liệu chạy MIKE 21 HD trong nghiên cứu này được chia ra làm 2 nhóm. Nhóm thứ nhất liên quan tới vùng ven biển được thu thập, xử lý và chuyển vào phần mềm MIKE21 [22], nhóm thứ hai liên quan tới đất liền và cửa sông gồm: số liệu thực đo 28 mặt cắt thực đo được kế thừa từ dự án trước đây [23-24]. Đoạn sông Vệ được xem xét trong nghiên cứu này được giới hạn từ thượng nguồn sông đến cửa Lở dài $21,47 \mathrm{~km}$ (Hình 3).

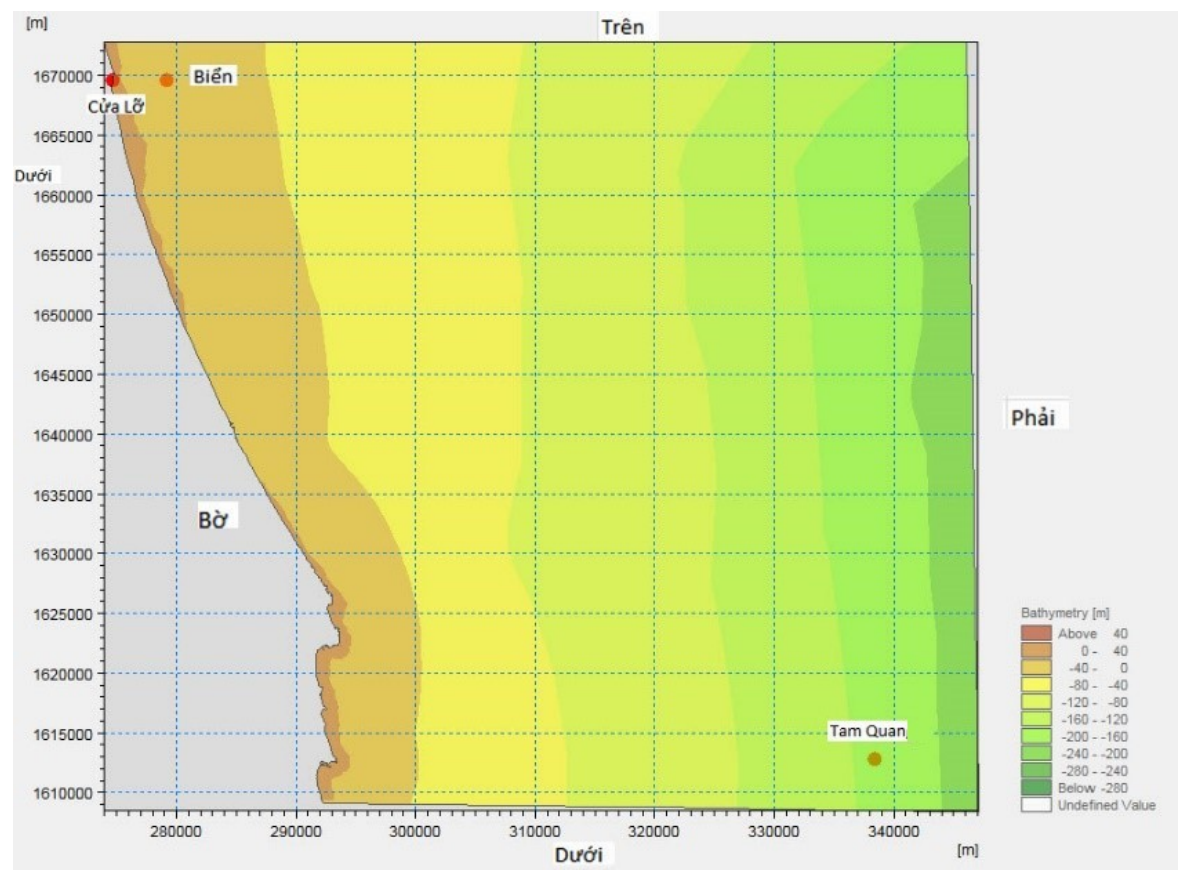

Hình 2. Địa hình biển được lựa chọn 


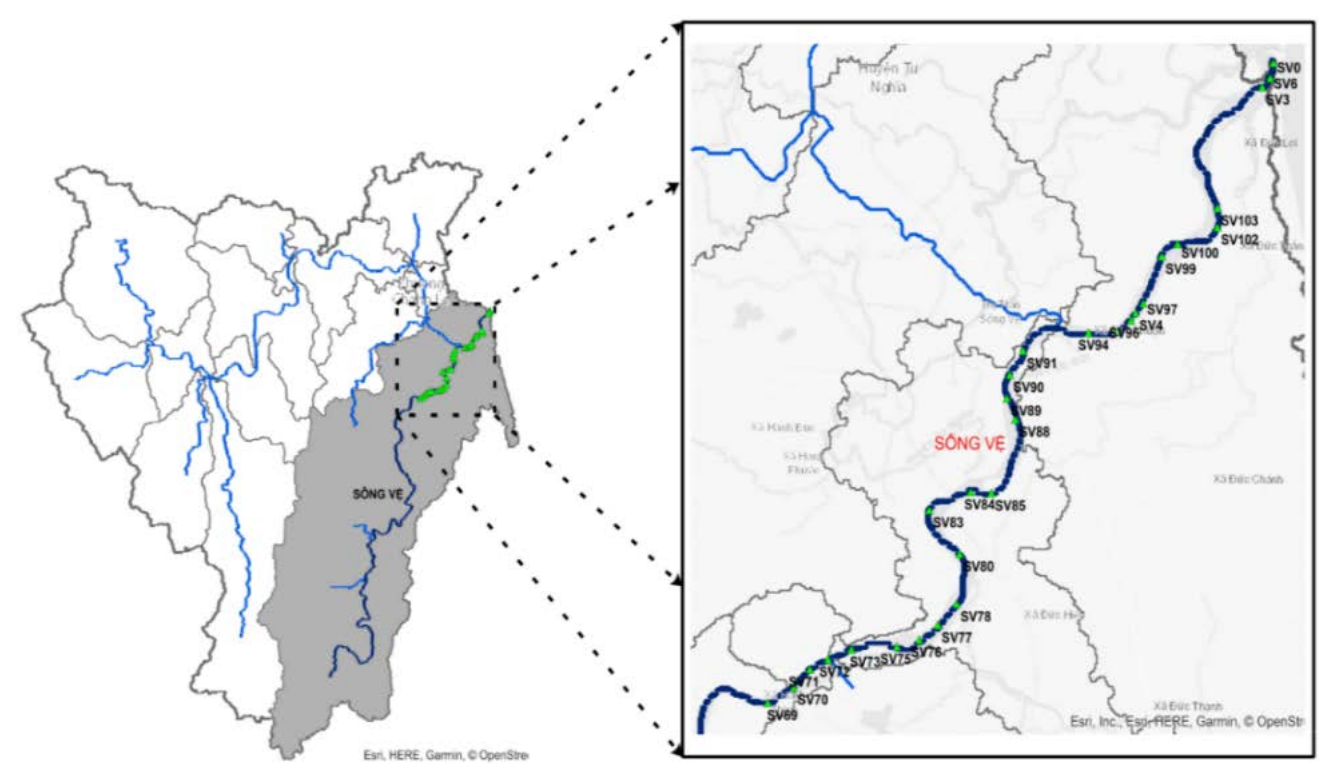

Hình 3. Địa hình vùng cưa sông và mặt cắt sông Vệ

\subsubsection{Dũ liệu khí tưọng - thủy văn}

Thông tin và số liệu khí tượng từ 02 trạm đo khí tượng thuộc tỉnh Quảng Ngãi là Ba Tơ và Quảng Ngãi trong các năm 2013 - 2015, thông tin và số liệu thủy văn thuộc trạm An Chỉ trong các năm 2013 - 2015 được sử dụng từ nguồn [25]. Các số liệu này đều có dạng các file thống kê thông dụng đã được xử lý đúng yêu cầu của các mô hình được sử dụng. Thông tin và số liệu hải văn từ trạm Tam Quan, Bình Định được ssử dụng để thực hiện nghiên cứu này được lấy từ tài liệu [26].

2.3.4 Dũ liệu biên thủy lực

$$
\mathrm{NSE}=\frac{\sum_{\mathrm{i}=1}^{\mathrm{n}}\left(\mathrm{Q}_{\mathrm{i}}^{\mathrm{sim}}-\mathrm{Q}_{\mathrm{i}}^{\mathrm{obs}}\right)^{2}}{\sum_{\mathrm{i}=1}^{\mathrm{n}}\left(\mathrm{Q}_{\mathrm{i}}^{\mathrm{obs}}-\overline{\mathrm{Q}}\right)^{2}},
$$

Trong nội dung chạy MIKE21 HD thuộc nghiên cứu này sử dụng dữ liệu biên mô hình thủy lực vùng ven bờ biển được lấy từ công cụ Tide Prediction of Height trong MIKE 21 Toolbox (.21t) cho năm 2015, 2017, 2018, nguồn [27]. Các dữ liệu này được sử dụng để chạy MIKE21 HD cho vùng ven biển nằm trong phạm vi nghiên cứu như được chỉ ra trên Hình 2.

\subsubsection{Chi tiêu đánh giá:}

Chỉ số đánh giá mức độ tương quan giữa kết quả tính toán và kết quả đo đạc, được xác định theo các công thức sau:

$P B I A S=\frac{\sum_{\mathrm{i}=1}^{\mathrm{n}}\left(\mathrm{Q}_{\mathrm{i}}^{\text {obs }}-\mathrm{Q}_{\mathrm{i}}^{\text {sim }}\right) \times 100}{\sum_{\mathrm{i}=1}^{\mathrm{n}}\left(\mathrm{Q}_{\mathrm{i}}^{\text {obs }}\right)}$

$$
\mathrm{RSR}=\frac{R M S E}{S T D E V_{\text {obs }}}=\frac{\sqrt{\sum_{\mathrm{i}=1}^{\mathrm{n}}\left(\mathrm{Q}_{\mathrm{i}}^{\text {obs }}-\mathrm{Q}_{\mathrm{i}}^{\text {sim }}\right)^{2}}}{\sqrt{\sum_{\mathrm{i}=1}^{\mathrm{n}}\left(\mathrm{Q}_{\mathrm{i}}^{\text {obs }}-\bar{Q}\right)^{2}}}
$$

Tiêu chuẩn đánh giá theo từng chỉ số trên được thể hiện trong bảng 1, nghiên cứu [28] sẽ được sử dụng trong nghiên cứu này.

2.3.6 Thiết lập mô hìn tạo bộ thông số thủy văn

Bộ thông số NAM được sử dụng trong nghiên cứu này gồm: $\mathrm{L}_{\max }$ : Lượng ẩm lớn nhất trong bể chứa tầng rễ cây; $\mathrm{U}_{\max }$ : Lượng nước tối đa trong bể trữ mặt, là lượng nước để điền trũng đọng trên mặt thực vật và chứa trong vài $\mathrm{cm}$ trên bề mặt của đất; CQOF: Hệ số dòng chảy mặt $(0 \leq \mathrm{CQOF} \leq 1)$, quyết định phân phối mưa hiệu quả cho dòng chảy mặt và thấm; CKIF: Hằng số thời gian của dòng chảy sát mặt cùng với $U_{\max }$ quyết định dòng chảy sát mặt. Nó chi phối thông số diễn toán dòng chảy trao đổi khi $\mathrm{CKIF}>>\mathrm{CK} 12$, trong đó $\mathrm{CK} 1,2$ : hằng số thời gian cho diễn toán dòng chảy mặt và dòng chảy 
sát mặt dọc theo các sườn dốc lưu vực và qua các lòng dẫn đến cửa ra của lưu vực. Ký hiệu $\mathrm{CKBF}$ : hằng số thời gian dòng chảy ngầm, để diễn toán hoàn trả nước thông qua lượng trữ nước ngầm, thường $\mathrm{CKBF}>>\mathrm{CK} 12$. Ký hiệu TOF: giá trị ngưỡng của dòng chảy mặt $(0 \leq \mathrm{TOF} \leq 1)$. Ký hiệu TIF: giá trị ngưỡng của dòng chảy sát mặt $(0 \leq \mathrm{TIF} \leq 1)$. Dòng chảy sát mặt chỉ hình thành khi chỉ số ẩm tương đối của đất ở tầng rễ cây lớn hơn TIF. Ký hiệu TG: giá trị ngưỡng của lượng nước bổ sung cho dòng chảy ngầm $(0 \leq \mathrm{TG} \leq 1)$. Lượng nước bổ sung cho bể chứa ngầm được hình thành khi chỉ số ẩm tương đối của đất ở tầng rễ cây lớn hơn TG [27]. Các thông số này dạng bảng được thể hiện trên Bảng 1.

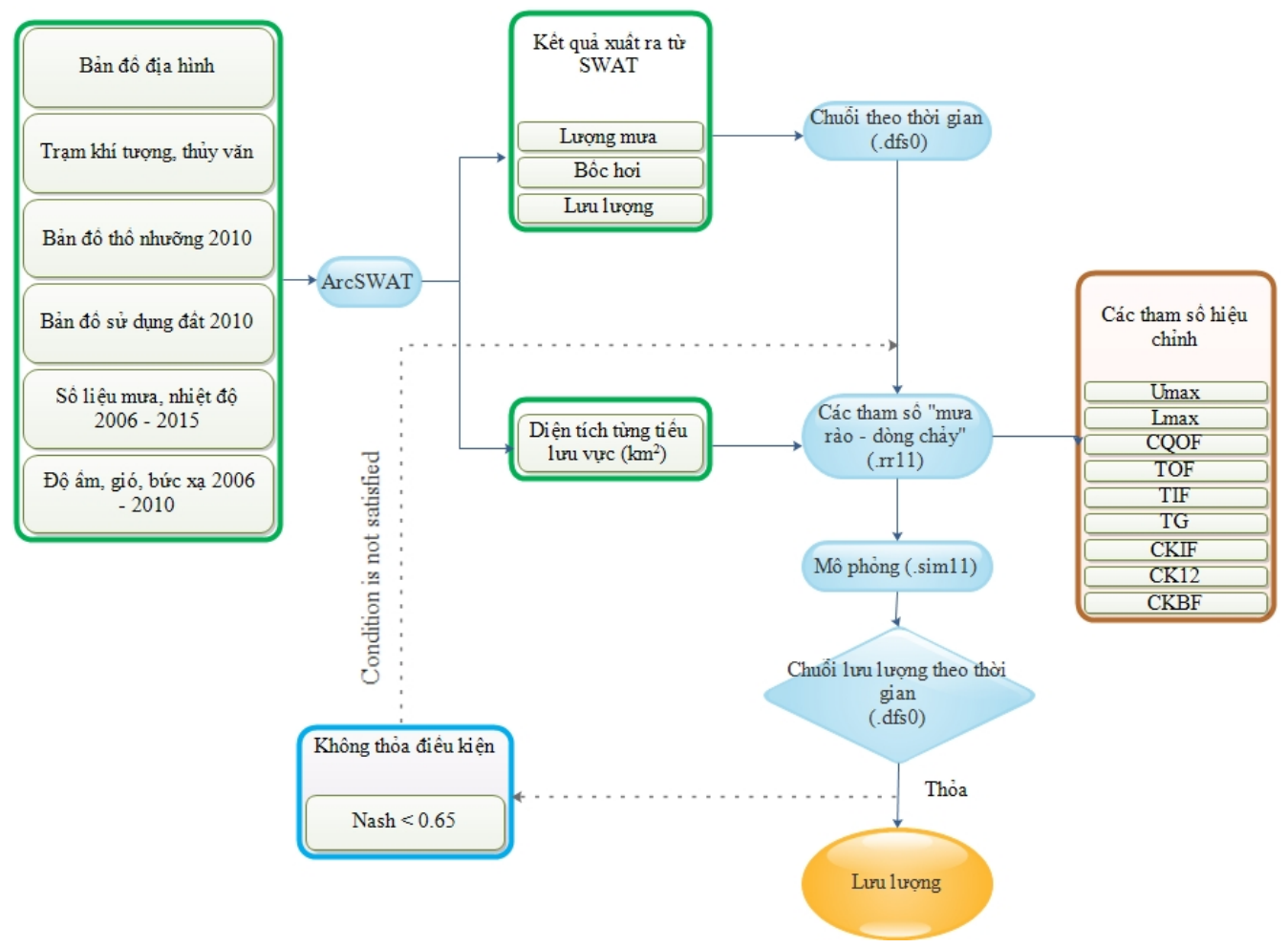

Hình 4. Các bước thiết lập bộ thông số thủy văn cho lưu vực

Các bước thiết lập mô hình lập ra bộ thông số thủy văn được thực hiện như sau: các dữ liệu đầu vào gồm bản đồ địa hình (DEM), số liệu khí tượng - thủy văn, bản đồ sử dụng đất, bản đồ thổ nhưỡng được đưa vào SWAT. Kết quả triết xuất ra sau khi chạy SWAT gồm diện tích các tiểu lưu vực kết hợp với số liệu mưa tại các trạm trong khu vực được đưa vào NAM (Hình 4) để thực hiện bước hiệu chỉnh các tham số của mô hình NAM. Sử dụng chỉ tiêu ở mục 2.3.5 để đánh giá độ tin cậy của bộ thông số. Để thực hiện hiệu chỉnh, trước tiên, từ bộ thông số ban đầu, NAM thực hiện hiệu chỉnh tự động bằng phương pháp thử dần để tăng tốc độ chính xác tới mức ổn định với sai số cho phép. Bộ thông số sau hiệu chỉnh của NAM sẽ được sử dụng để tính toán biên lưu lượng cho mô hình thủy lực tiếp theo. Một số kết quả của nội dung này được trình bày trong [19].
2.3.7 Thiết lập mô hình tạo biên cho mô hình thüy luc MIKE21 HD

Biên trên được xác định ở tiểu lưu vực số 9 có lưu ý tới những nhánh sông phụ chảy vào nhánh sông ở các tiểu lưu vực $8,10,11,12$ (Hình 1). Từ mô hình SWAT tính toán được tổng diện tích các lưu vực trên. Số liệu mưa và bốc hơi ngày được lấy ở trạm khí tượng $\mathrm{Ba}$ Tơ. Do những điểm hợp lưu nằm ở vùng hạ lưu sông Vệ nên mưa được lấy từ trạm khí tượng Quảng Ngãi và bốc hơi được tính ra tương ứng với các tiểu lưu vực bằng sự hỗ trợ từ SWAT. Từ bộ thông số NAM đã được hiệu chỉnh và kiểm định trong mục 2.3.6, cùng với 2 dạng chuỗi theo thời gian lượng mưa, bốc hơi vào mô hình NAM. Các bước tạo ra file biên lưu lượng tại thượng lưu được thể hiện trên Hình 5. 


\section{BÀI BÁO KHOA HỌC}

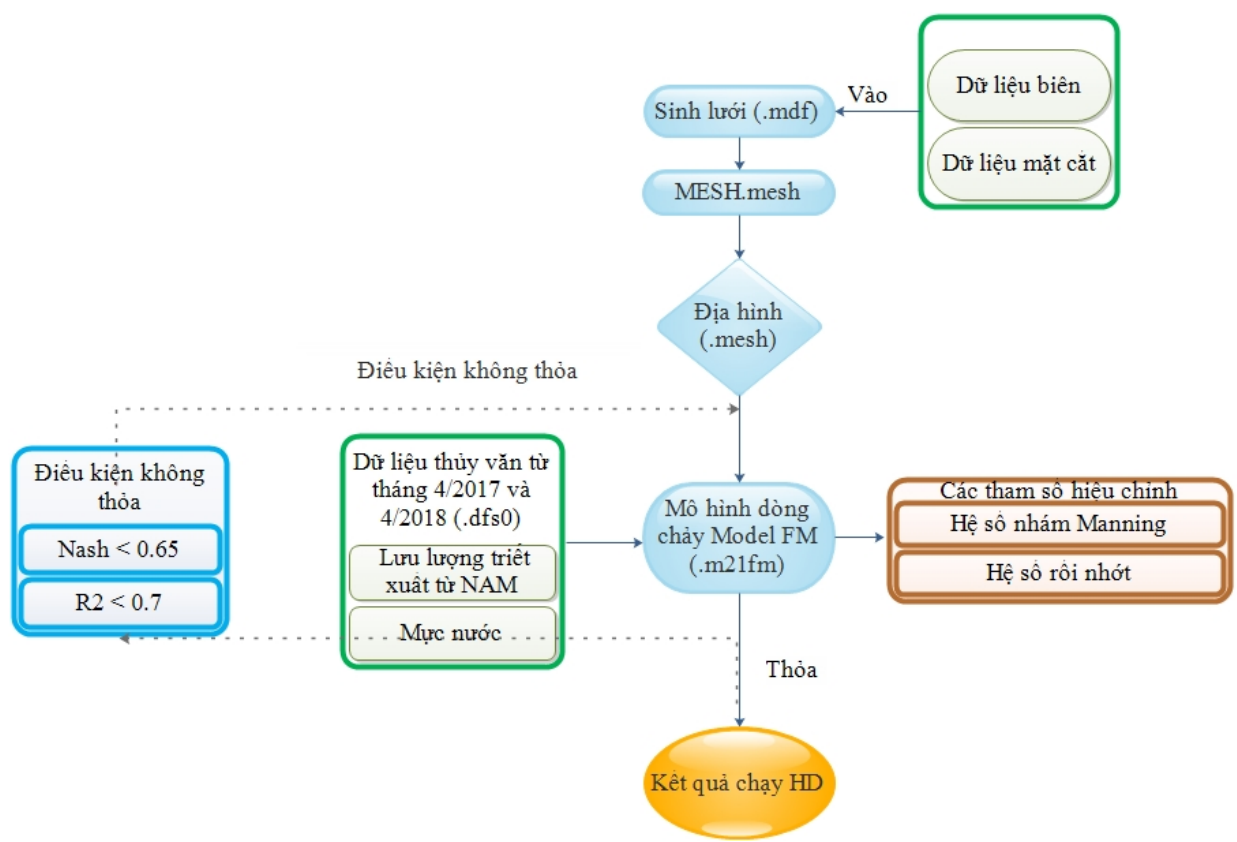

Hình 5. Các bước thiết lập hệ thống mô hình diễn toán SWAT, NAM tạo biên lưu lương cho mô hinh thuy luce

Sử dụng dữ liệu biên cho mô hình thủy lực mô hình thủy lực vùng ven bờ biển từ công cụ vùng ven bờ biển (Hình 2) được lấy từ công cụ Tide Prediction of Height trong MIKE 21 Toolbox(.21t) cho năm 2015, nguồn [27]. Thực hiện Tide Prediction of Height trong MIKE 21Toolbox(.21t) cho các năm cần tính để xuất kết quả mực nước tại vị trí cửa Lở, sông Vệ. Các bước bước hiệu chỉnh và kiểm mô hình thủy lực thiết lập này được thể hiện trên Hình 6. MIKE21 HD. Sau đó sử dụng dữ liệu biên cho

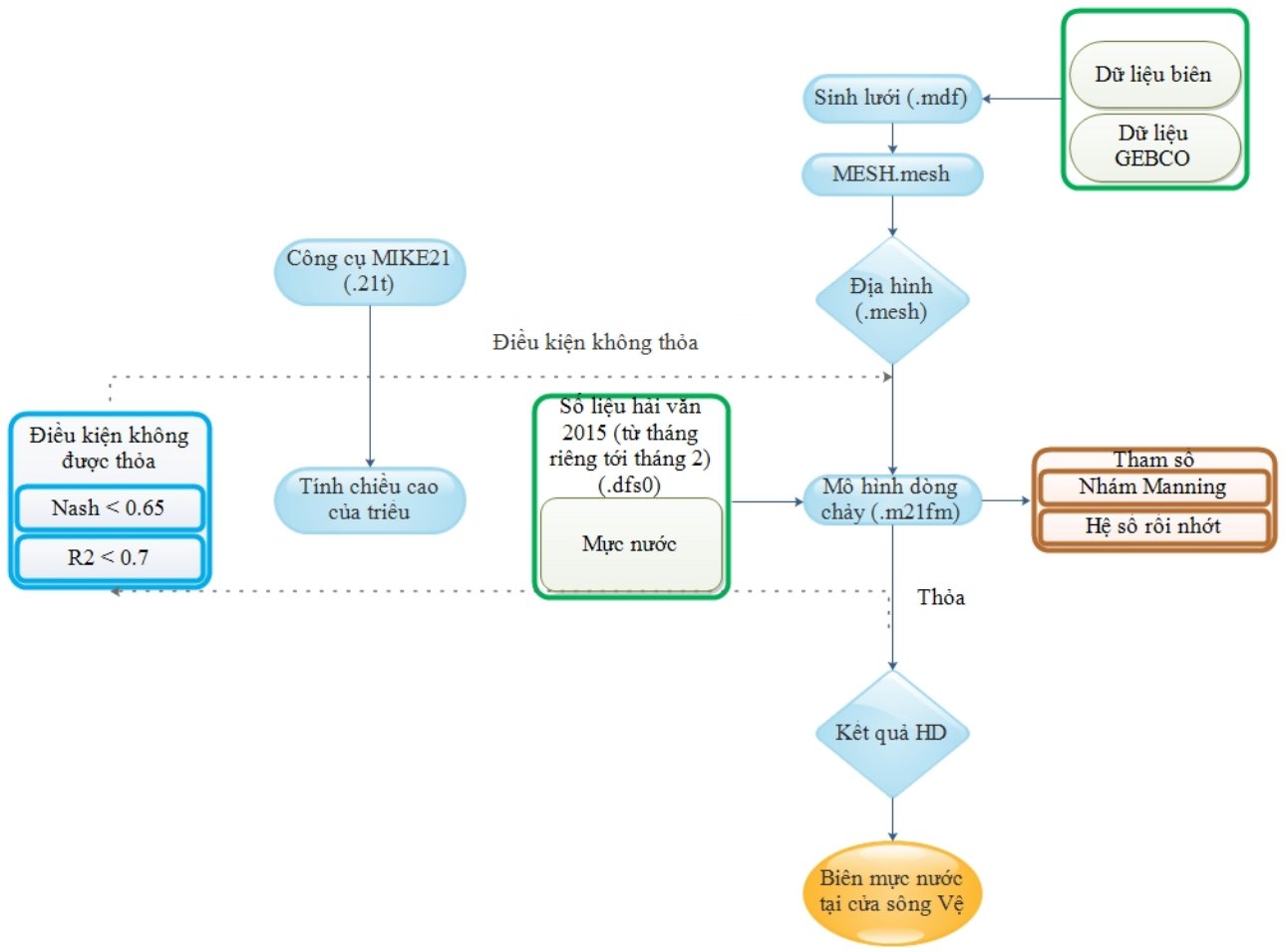

Hình 6. Các bước thiết lập hệ thống mô hình diễn toán MIKE21 HD tạo mực nước cho mô hình thuy lucc 
2.3.8 Thiết lập mô hình hiểu chỉnh và kiểm định thông số thủy lực

Trong nghiên cứu này, hệ số nhám manning và hệ số nhớt rối được lựa chọn làm thông số thủy lực. Từ bộ thông số thủy văn đã được hiệu chỉnh và kiểm định trong mục 2.3.6, cùng với biên lưu lượng và mực nước được tạo ra từ 2.3 .7 sẽ giúp vận hành MIKE $21 \mathrm{HD}$ cho sông Vệ. Dựa trên số liệu thực đo thủy văn tại trạm An Chỉ để hiệu chỉnh và kiểm định bộ thông số thủy lực.

\section{Kết quả và thảo luận}

\subsection{Hiệu chỉnh và kiểm định mô hình NAM}

Bộ dữ thủy văn thực đo ở trạm An Chỉ, trong giai đoạn 2013-2015 được sử dụng để hiệu chỉnh và kiểm định NAM. Để đánh giá mức độ tương quan, trong nghiên cứu này sử dụng chỉ số Nash (các nghiên cứu tương tự được thực hiện trong [6], [15], [16]). Bộ số liệu thực đo lưu lượng năm 2013 được sử dụng để hiệu chỉnh và đạt chỉ số NASH là $92 \%$. Bước kiểm định được thực hiện theo số liệu đo lưu lượng trong 2 năm 2014 và 2015 đạt chỉ số NASH lần lượt là $90 \%$ và 93\%. Kết quả bộ thông số được chọn để mô phỏng lưu lượng được thể hiện trên Bảng 2 . Kết quả hiệu chỉnh và kiểm định được thể hiện trên các Hình 7 - Hình 9.

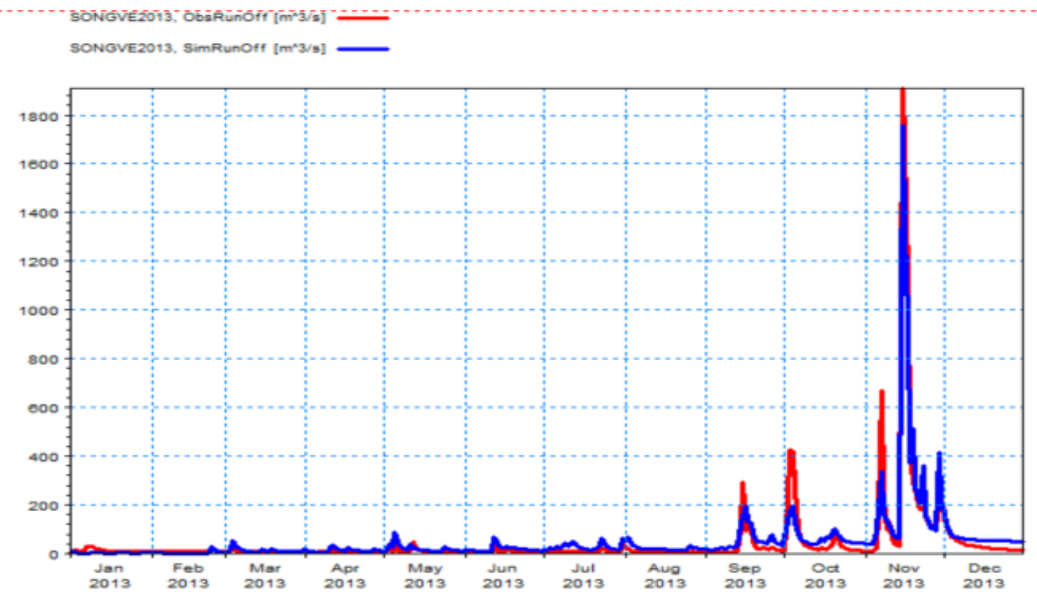

Hình 7. Biểu đồ quá trình lưu lương thục đo và tính toán theo NAM năm 2013

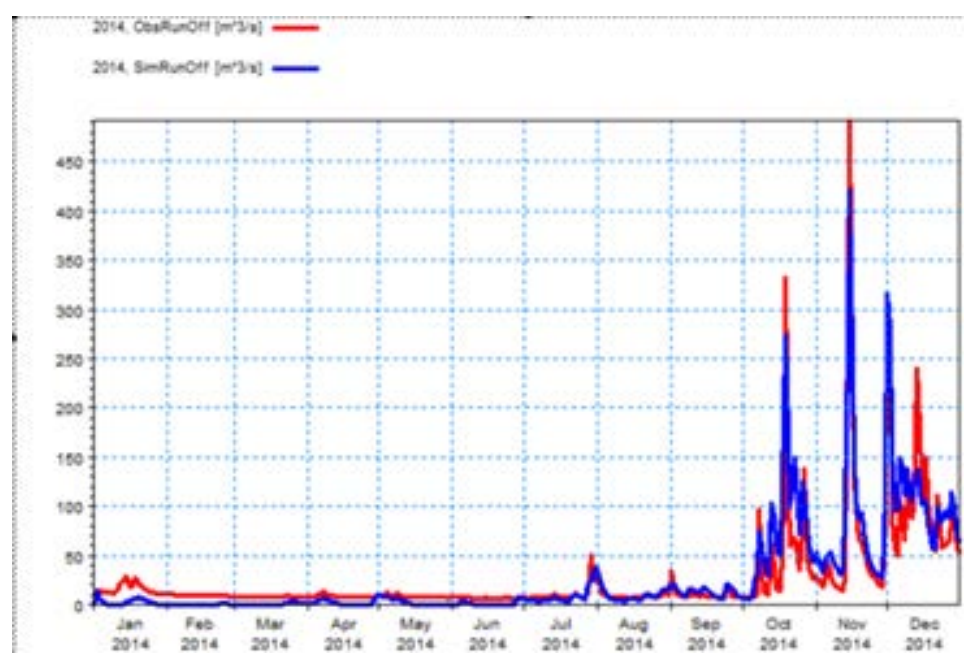

Hình 8. Biểu đồ quá trình lưu lượng thục đo và tính toán theo NAM năm 2014 


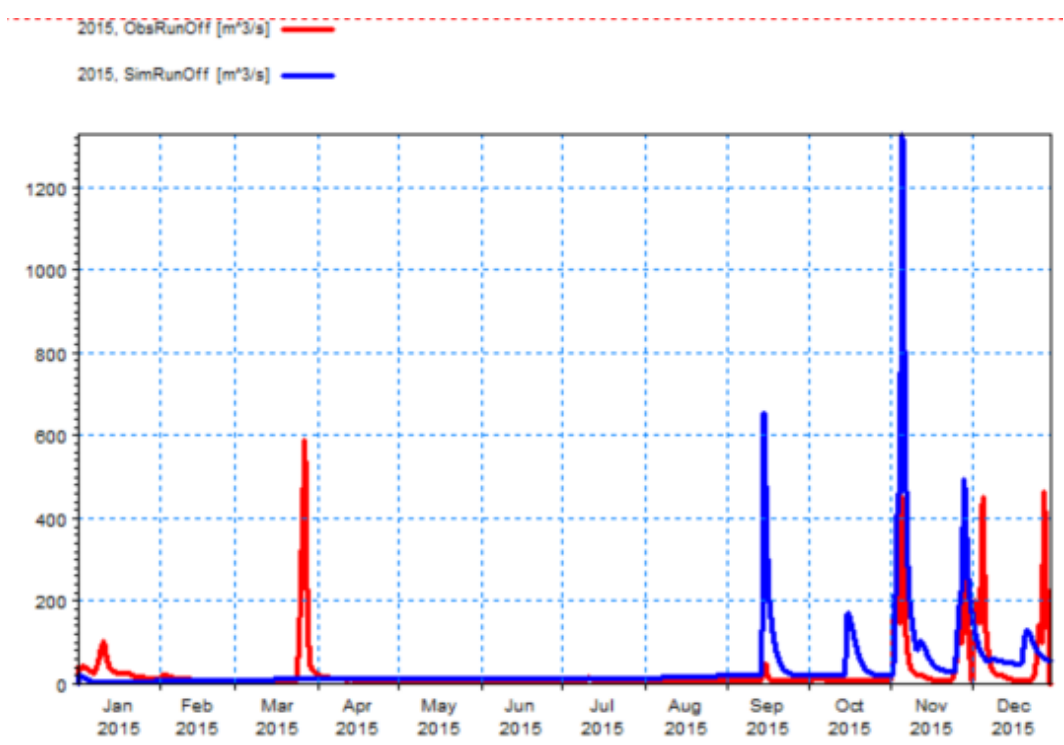

Hình 9. Biểu đồ quá trình lưu lượng thục đo và tính toán theo NAM năm 2015

Bảng 1. Bảng kết quả thông số của mô hình MIKE NAM

\begin{tabular}{clc}
\hline $\begin{array}{c}\text { Thông } \\
\text { số }\end{array}$ & \multicolumn{1}{c}{ Ý nghĩa } & Giá trị \\
\hline $\mathrm{U}_{\max }$ & Lượng nước tối đa trong bể chứa mặt $(\mathrm{mm})$ & 17 \\
\hline $\mathrm{L}_{\max }$ & Lượng ẩm lớn nhất trong bể chứa tầng rễ cây $(\mathrm{mm})$ & 172 \\
\hline CQOF & $\begin{array}{l}\text { Hệ số dòng chảy mặt, không thứ nguyên, phản ánh điều kiện } \\
\text { thấm }\end{array}$ & 0,185 \\
\hline TOF & Ngưỡng dưới của dòng chảy tràn & 0,531 \\
\hline TIF & Ngưỡng dưới của dòng chảy sát mặt & 0,114 \\
\hline TG & Giá trị ngưỡng tầng rễ cây & 0,404 \\
\hline CKIF & Hệ số thời gian dòng chảy sát mặt & 655,8 \\
\hline CK12 & Hằng số thời gian chảy truyền của dòng chảy mặt & 19 \\
\hline CKBF & Hằng số thời gian chảy truyền của dòng chảy ngầm & 3972 \\
\hline
\end{tabular}

Kết quả được chỉ ra bảng 1 có sự tương đồng với kết quả do nhóm tác giả Linh và cs (2018) chỉ ra trong [2], sử dụng cách tiếp cận khác. Bộ thông số này đảm bảo độ chính xác cũng như tính ổn định để có thể sử dụng mô phỏng dòng chảy thượng lưu cho các năm khác và bộ thông số này được dùng để tính toán dòng chảy tại các phụ lưu khu giữa làm biên đầu vào cho mô hình dòng chảy cũng như lan truyền chất.

\subsection{Hiệu chinh, kiểm định Mike 21 HD}

Bảng 2. Kết quả kiểm định và hiệu chỉnh mô hình thủy lục MIKE21 HD cho vùng ven biển

\section{vùng ven bò̀ biển}

Chuỗi số liệu biên được lựa chọn như sau: thời gian chọn để hiệu chỉnh: 1/1/2015 28/2/2015; thời gian chọn cho kiểm định: 1/3/2015 - 31/5/2015, như được chỉ ra trong mục 2.3.7. Dữ liệu thực đo mực nước tại trạm Tam Quan được sử dụng để hiệu chỉnh và kiểm định [26]. Kết quả hiệu chỉnh và kiểm định theo mục 2.3.5 được thể hiện trong Bảng 2 và Hình 10 .

\section{Hệ số tương quan Hệ số Nash PBIAS (\%) RSR}

\begin{tabular}{lllll}
\hline Hiệu Chỉnh & 0,916 & 0,988 & 7,323 & 0.460 \\
Kiểm Định & 0,919 & 0,991 & 7,933 & 0.490 \\
\hline
\end{tabular}


Kết quả, bộ thông số được lựa chọn như sau: hệ số nhớt $0,28\left(\mathrm{~m}^{2} / \mathrm{s}\right)$, hệ số nhám $30(\mathrm{~m} 1 / 3 / \mathrm{s})$.

3.3 Hiệu chỉnh, kiểm định vùng cửa sông Vệ

Chuỗi số liệu biên được lựa chọn để chạy MIKE21 HD như sau: chuỗi thời gian cho hiệu chỉnh: 1/4/2017 - 30/4/2017; thời gian chọn cho kiểm định: 1/4/2018 - 30/4/2018. Biên trên (lưu lương) được trích xuất từ kết quả chạy NAM cho phạm vi từ $1-30 / 4 / 2017$ và $1-30 / 4 / 2018$. Biên đước (mực nước) được triết xuất từ kết quả chạy thủy lực cho khu vực biển được mô tả trong mục 2.3.5 của bài báo này. Dữ liệu thực đo dùng để hiệu chỉnh và kiểm định mô hình là dữ liệu dưới dạng chuỗi thời gian đo mực nước tại trạm Sông Vệ [25] (mỗi bước là 1 giờ). Kết quả của mục này là chọn bộ thông số hệ số nhớt bằng 0.28 và hệ số nhám Manning bằng $32 \mathrm{~m} 1 / 3 / \mathrm{s}$. Kết quả hiệu chỉnh và kiểm định theo mục 2.3.5 được thể hiên trong Bảng 3 và Hình 10, dựa trên [28] có thể kết luận đảm bảo độ tin cậy.

Bảng 3. Kết quả kiểm định và hiệu chỉnh mô hình thủy lục MIKE21 HD sông Vệ

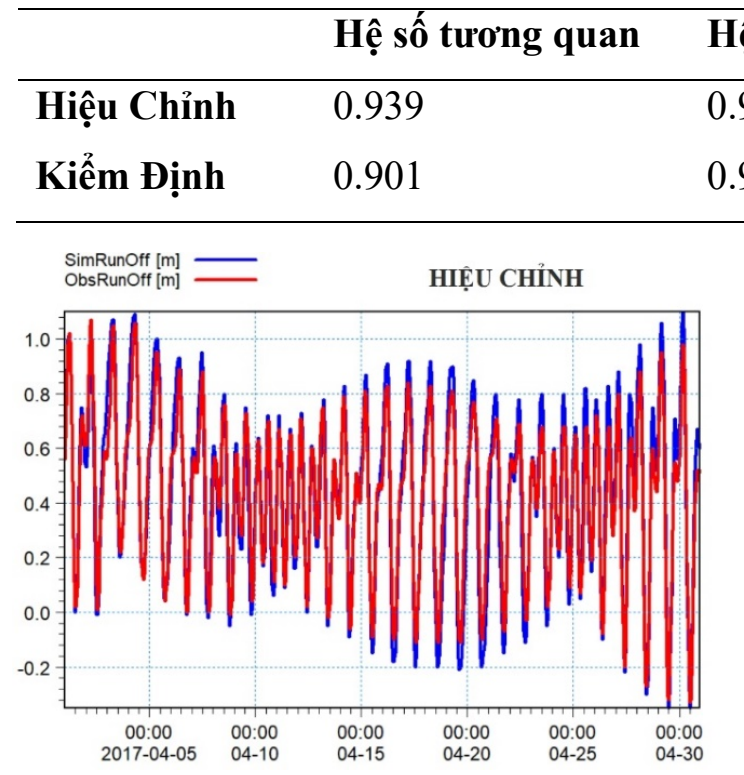

\section{Hệ số Nash $\quad$ PBIAS $<10 \% \quad$ RSR $<0.5$}

\begin{tabular}{lllll}
\hline Hiệu Chỉnh & 0.939 & 0.970 & -2.290 & 0.490 \\
Kiểm Định & 0.901 & 0.953 & -16.763 & 0.490 \\
\hline
\end{tabular}

Hình 10. Biểu đồ mưc nuớc lúc hiệu chỉnh, kiểm định tại trạm Sông Vệ

\section{Kết luận}

Các kết quả đạt được trong nghiên cứu này gồm, thứ nhất đưa ra quy trình các bước tính theo mô hình diễn toán, kết hợp các dữ liệu đo đạc thực tế nhằm xây dựng được bộ thông số thủy văn, thủy lực tại khu vực của sông Vệ phục vụ cho diễn toán dòng chảy. Thứ hai, thực hiện hiệu chỉnh, kiểm đ̛̣inh NAM và tìm ra bộ thông số thủy văn ổn định, đáp ứng được yêu cầu chỉ số thống kê, có thể sử dụng cho tính toán dòng chảy, đã sử dụng mô hình SWAT và công cụ ArcGIS. Thứ ba, thực hiện hiệu chỉnh, kiểm định bộ thông số thủy lực thông qua sử dụng mô hình MIKE21

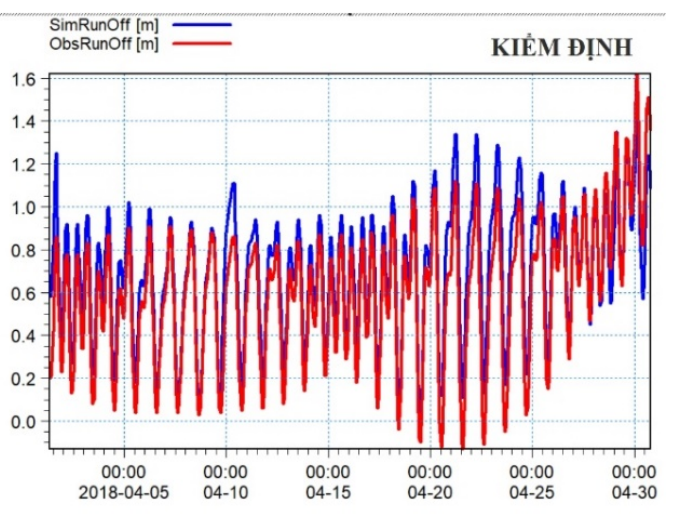

HD. Kết quả hiệu chỉnh và kiểm định được đánh giá định lượng thông qua các chỉ số thống kê đều đạt mức chính xác cao hay thỏa yêu cầu. Hạn chế của nghiên cứu là số liệu thực đo còn hạn chế và hướng khắc phục trong bài báo tiếp theo là đo đạc thực tế tại một số vị trí khác trên sông Vệ để kiểm định độ tin cậy của các bộ số liệu được đưa ra. Kết quả của bài báo là sự nỗ lực nghiên cứu của nghiên cứu sinh và tập thể giảng viên hướng dẫn. Dù có nhiều nỗ lực nhưng cũng khó tránh khỏi sai sót. Rất mong sự đóng góp ý kiến của các chuyên gia để nâng cao chất lượng kết quả nghiên cứu.

Lời cảm ơn: Nghiên cưu này được thực hiện nhờ sụ động viên, góp ý kiến và chỉ dẫn của các thầy tù Viện Khoa học và Thủy lợi miền Nam nơi tác giả đang học Nghiên cứu sinh. Bộ số liệu đo được sủ dụng trong nghiên cứu được nhóm mua tù các đơn vị chưc năng được ghi rõ trong phần trích dẫn. Nhóm tác giả xin bày tỏ sụ cảm ơn trân thành tới các thầy, Viện và các đơn vị cung ưng số liệu. 


\section{BÀI BÁO KHOA HỌC}

\section{Tài liệu tham khảo}

1. Cao Đăng Dư (2006), Xây dụng công nghệ dụ báo lũ lón và cảnh báo ngập lụt hệ thống sông Vệ - Trà Khúc, thử nghiệm và chuyển giao công nghệ. Báo cáo tổng kết đề tài cấp nhà nước, 116 trang.

2. Linh, N.T.M., Tri, D.Q., Thai, T.H., Don, N.C. (2018), Application of a two-dimensional model for flooding and floodplain simulation: Case study in Tra Khuc-Song Ve river in Viet Nam. Lowland Technology International, 20 (03), 367-378.

3. Trương Văn Bốn, Vũ Văn Ngọc, Vũ Phương Quỳnh, Trần Mạnh Trường (2018), Các quá trình động lục và diễn biến hình thái cưa Đại và cửa Lở tỉnh Quảng Ngãi. Tạp Chí Khoa Học Và Công Nghệ Thủy Lợi, 48, 7-15.

4. Vũ Phương Quỳnh, Vũ Văn Ngọc, Trương Văn Bốn, Trần Mạnh Trường (2018), Diê̂n biến nguõng cát di động tại của Đại \& cưa Lở tỉnh Quảng Ngãi qua ảnh vệ tinh. Tạp Chí Khoa Học Và Công Nghệ Thủy Lợi, 48, 16-24.

5. Nguyễn Mạnh Linh, Đỗ Anh Đức, Nguyễn Ngọc Bách (2013), Đánh giá ảnh hưởng tiêu thoát lũ tỉnh Quảng Ngãi khi xây dụng tuyến đường cao tốc Đà Nã̃ng - Quảng Ngãi. Tạp Chí Khoa Học Và Công Nghệ Thủy Lợi, 13, 44-51.

6. Bùi Văn Chanh, Trần Ngọc Anh (2016), Tích hợp bộ mô hình dụ báo thủy văn lưu vực sông Trà Khúc. Tạp chí Khoa học ĐHQGHN: Các Khoa học Trái đất và Môi trường, 32 (3S), 20-25.

7. Nayak, P.C., Venkatesh, B., Krishna, B., Jain, S.K. (2013), Rainfall-runoff modeling using conceptual, data driven, and wavelet based computing approach. Journal of Hydrology, 493, 57-67.

8. Madsen, H. (2000), Automatic calibration of a conceptual rainfall-runoff model using multiple objectives. Journal of Hydrology, 235, 276-288.

9. Makungo, R. , Odiyo, J.O., Ndiritu, J.G., Mwaka, B. (2010), Rainfall-runoff modelling approach for ungauged catchments: A case study of Nzhelele River sub-quaternary catchment. Physics and Chemistry of the Earth, 35, 596-607.

10. Bennett, J.C., Robertson, D.E., Phillip, G.D., Ward, H.A., Prasantha Hapuarachchi, Wang, Q.J. (2016), Calibrating hourly rainfall-runoff models with daily forcings for streamflow forecasting applications in meso-scale catchments. Environmental Modelling \& Software, 76, 20-36.

11. Samadi, A., Sadrolashrafi, S.S., Kholghi, M.K. (2019), Development and testing of a rainfallrunoff model for flood simulation in dry mountain catchments: A case study for the Dez River Basin. Physics and Chemistry of the Earth, 109, 9-25.

12. Chang, T.J., Chang, Y.S., Chang, K.H. (2016), Modeling rainfall-runoff processes using smoothed particle hydrodynamics with mass-varied particles. Journal of Hydrology, 543 (B), 749758.

13. Boughton, W.C. (2007), Effect of data length on rainfallerunoff modelling. Environmental Modelling \& Software, 22, 406 -413.

14. Bruins, H.J., Hodaya, B.G., Svoray, T. (2019), GIS-based hydrological modelling to assess runoff yields in ancient-agricultural terraced wadi fields (central Negev desert). Journal of Arid Environments, 166, 91-107.

15. Đinh Xuân Trường (2010), Úng dụng mô hình Nam Mikell dụ báo dòng chảy cho các lưu vục bộ phận trên lưu vưc sông Ba. Tạp chí Khí tượng Thủy văn, số 11/2010 (599), trang 50-55.

16. Trần Duy Kiều, Đinh Xuân Trường (2011), Úng dụng mô hình Nam_Mikel1 dụ báo dòng chảy tại Yên Thượng trên lưu vực sông Cả. Tạp chí Khí tượng Thủy văn, 606, 37-41.

17. Trần Tuấn Hoàng, Bùi Chí Nam, Ngô Nam Thịnh (2012), Nghiên cứu tính toán "mưa rào dòng chảy” hạ lưu sông Sài Gòn làm đầu vào cho bài toán chống ngập 10 (622), 17 - 21. 
18. Singh, V.P. (1995), Watershed Modeling. In: Singh, V.P. (Ed.), In Computer Models of Watershed Hydrology. Water Resources Publications, Littleton, Colo., pp. 1-22.

19. Lê Thịi Mỹ Diệp (2017), Báo cáo kết quả thục hiện nhiệm vụ nghiên cúu 6 tháng cuối năm (chuyên đề 2), 75 trang.

20. Nguyễn Thị Ngọc Quyên, Nguyễn Duy Liêm, Bùi Tá Long, Nguyễn Kim Lợi (2017), Mô phỏng chế độ dòng chảy và bồi lắng dưới tác động của các công trình hồ chứa chính trên lưu vực sông Srepok". Tạp chí Khoa học, 26, 18-26.

21. Nguyễn Văn Phước, Nguyễn Thanh Hùng, Bùi Tá Long (2011), Phuơng pháp tính toán thiệt hại về kinh tế và môi truờng đối với một lưu vục sông bị ônhiếm - Trương hợp điển hình: lưu vục sông Thị Vải. Tạp chí Phát Triển Khoa Học \& Công Nghệ, (M1), 5-28.

22. GEBCO (2017), "GEBCO - The General Bathymetric Chart of the Oceans." 2017 https://www.gebco.net/.

23. Viện Quy hoạch Thủy lợi (2013), Báo cáo tổng hơp dự án: "Quy hoạch điều chỉnh, bổ sung thủy lợi tỉnh Quảng Ngãi đến 2020”. Viện Quy hoạch Thủy lợi, Hà Nội.

24. ĐKSKTTV II (Đoàn khảo sát khí tượng thủy văn II) (2019), Báo cáo đo đạc khảo sát địa hình lòng sống và các yếu tố thủy văn tại hạ lư sông Vệ, tỉnh Quảng Ngãi.

25. Trạm Khí tượng thủy văn Quảng Ngãi.

26. TTKTTVB (Trung Tâm Khí Tượng Thủy Văn Biển) (2015), Thủy triều.

27. DHI (Danish Hydraulic Institute) (2014), MIKE 11, 21 Flow Model - User Guide (DHI Agent).

28. Moriasi, D.N., Arnold, J.G., Van Liew, M.W., Bingner, R.L., Harmel, R.D., Veith, T.L. (2007), Model evaluation guidelines for systematicquantification of accuracy in watershed simulations. American Society of Agricultural and Biological Engineers, 50 (3), 885-900.

\title{
APPLYING MATHEMATICAL MODELS SWAT/NAM/MIKE TO BUILD HYDROLOGICAL AND HYDRAULIC PARAMETERS FOR FLOW CALCULATION - IN CASE OF VE RIVER, QUANG NGAI
}

\author{
Le Thi My Diep', Bui Huynh Anh², Bui Ta Long²* \\ ${ }^{1}$ The Southern Institute Of Water Resources Research \\ ${ }^{2}$ Hochiminh city University of Technology
}

\begin{abstract}
Relatively fast economic growth is observed in the coastal zone of Quang Ngai province. Under the influence of climate change, flooding and salt intrusion are becoming more complicated. Both of these types require calculation and prediction of the flow; therefore, they are the subject of research by many authors. In this study, the proposed procedure is the application of the system of models SWAT, NAM and MIKE, which is calibrated and verified using actual measurement data and, ultimately, to build a set of hydrological and hydraulic parameters to calculate the flow of the Ve river. Calibration and verification results are based on widely used statistical indexes, which allow us to confirm that actual applicability is acceptable. A new feature of this study compared to previous studies is shown in the integrated diagram, which clearly shows the combination of data, models and steps for setting hydrological and hydraulic parameters.
\end{abstract}

Keywords: Rain-Runnoff, SWAT, NAM, MIKE, Ve river. 